\title{
(2) A rare case of urachal adenocarcinoma with bone OPEN ACCESS \\ marrow metastasis
}

\author{
Joshua Van Allen ${ }^{1,2}$
}

\begin{abstract}
'Department of Medicine, University of Connecticut Health Center, Farmington, Connecticut, USA

${ }^{2}$ Hartford HealthCare Cancer Institute at The Hospital of Central Connecticut, Plainville, Connecticut, USA
\end{abstract}

\section{Correspondence to} Dr. Joshua Van Allen; jvanallen@uchc.edu

Accepted 6 April 2021

Check for updates

(c) BMJ Publishing Group Limited 2021. Re-use permitted under CC BY-NC. No commercial re-use. See rights and permissions. Published by BMJ.

To cite: Van Allen J. BMJ Case Rep 2021;14:e242315. doi:10.1136/bcr-2021242315

\section{SUMMARY}

Urachal cancer is a rare and aggressive cancer that often presents in advanced stages. Given the rarity of this malignancy, medical case studies provide one of the few sources of literature available through which clinicians can guide medical management. Surgery is widely considered to be the mainstay of therapy when disease is localised and surgically resectable, therefore most current case studies on urachal cancer focus on surgical management, occasionally with adjuvant chemotherapy. However, few case studies discuss chemotherapy alone in the treatment of metastatic disease. Most studies indicate a median overall survival between 12 and 24 months for metastatic urachal adenocarcinoma. Bone marrow metastasis of solid tumours, when considered alone, portends a poor prognosis. The patient in this case study represents a rare case of stage IV urachal adenocarcinoma metastatic to the bone marrow without progression of disease after 6 months of treatment.

\section{BACKGROUND}

The urachus is a fibrous, tubular vestigial remnant derived from the involution of two contiguous embryonic structures, one of which is the allantois, a derivative of the yolk sac, and the other being the cloaca, a cephalic extension of the urogenital sinus which is a precursor to the fetal bladder. ${ }^{1-3}$ The urachus usually involutes after the third trimester and is obliterated by fibrous proliferation thus remaining as the medial umbilical ligament, connecting the apex of the bladder dome to the umbilicus in the midline, without any remaining physiological function. ${ }^{245}$

Urachal cancer is a rare, aggressive and often clinically silent disease due to its extravesical and extraperitoneal location. ${ }^{167}$ It accounts for less than $0.5 \%$ of bladder cancers and only $0.01 \%$ of all adult malignancies. ${ }^{6} 89$ Urachal cancer typically involves the dome of the bladder and is most often histologically characterised as adenocarcinoma in $80 \%-90 \%$ of cases, although the normal urachus is primarily lined by transitional epithelium. ${ }^{2410}$ One proposed theory is that this occurs due to columnar metaplasia of the urachal mucosa while a competing theory suggests that this is due to malignant transformation of enteric epithelial rests within the urachal remnant left behind from the cloaca during embryological development. ${ }^{2611}$ Histological subtype of urachal cancer most often reveals mucinous type in 50\%-75\% of cases, although $15 \%-25 \%$ of cases are enteric type, resembling colorectal adenocarcinomas and 6\%-7\% are signet ring cell type. ${ }^{1012} 13$ The median age at the time of diagnosis is between 50 and 58 years old based on previous studies, which is much younger than non-urachal adenocarcinomas whose median age is around 69 years old. ${ }^{10}{ }^{14}$ Urachal cancer also displays male predilection, with males representing between $60 \%$ and $68 \%$ of all cases. ${ }^{78}$

Patients with urachal cancer often present with locally advanced or metastatic disease, most commonly metastatic to the lungs, liver, peritoneum, lymph nodes, brain and/or bone. ${ }^{6} 81213$ Given the aggressive nature of urachal cancer, early diagnosis is paramount as there is significant divergence in both treatment and prognosis depending on stage. A retrospective study performed by Mayo Clinic in Rochester, Minnesota evaluated 49 patients with urachal cancer from 1950 to 2003 and found the median overall survival for stage I/ II urachal cancer to be 10.8 years vs 1.3 years for stage IV urachal cancer. ${ }^{8}$

\section{CASE PRESENTATION}

A 52-year-old man with a medical history of hypertension presented to an outpatient office with shortness of breath with exertion for about 4 weeks. He also endorsed 12 pound intentional weight loss over the previous 5 months. This patient denied any haematuria, haematochezia, melena, night sweats, cough or haemoptysis. $\mathrm{He}$ was a non-smoker, reported infrequent alcohol use and reported no drug use. The patient's mother had Hodgkin lymphoma and small-cell lung cancer, his brother had testicular cancer and his aunt had ovarian cancer. Outpatient laboratory studies were performed which revealed pancytopenia. The patient was subsequently sent to the hospital for further evaluation.

\section{INVESTIGATIONS}

CT scan of the chest, abdomen and pelvis with IV and PO contrast was performed and revealed a mixed density soft tissue mass measuring 7.2 $\mathrm{cm} \times 2.8 \mathrm{~cm} \times 3.2 \mathrm{~cm}$ arising from the anterior superior dome of the bladder in the midline extending toward the umbilicus along the course of the urachal remnant with punctate calcifications but without visible extension into the lumen of the bladder (figure 1). The CT scan also revealed multiple lung nodules and numerous hepatic hypodensities scattered throughout the liver both of which were concerning for metastases. There was no radiographic evidence of bone metastasis.

Given the patient's pancytopenia and clinical presentation, bone marrow aspirate and biopsy were performed which revealed $90 \%-95 \%$ of the marrow space largely replaced by mucin within which were glandular structures composed of malignant cells 

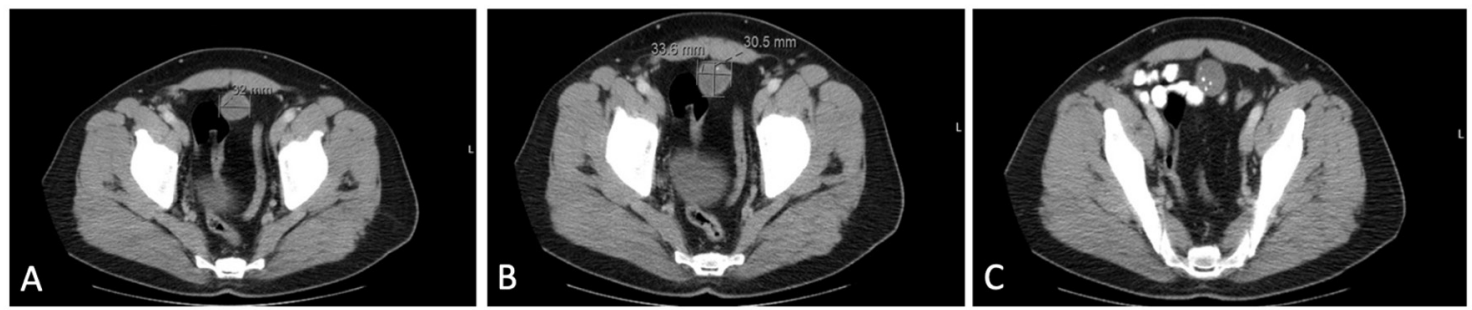

Figure 1 CT scan of the chest, abdomen and pelvis with IV and PO contrast revealed a mixed density soft tissue mass inseparable and arising from the anterior superior dome of the bladder extending cephalad in the midline toward the umbilicus along the course of the urachal remnant with punctate internal calcifications and no visible extension into the lumen of the bladder.

including frequent signet-ring forms (figure 2). Immunohistochemical staining was positive for CK20, CDX2 and P504S and negative for CK7, TTF1 and CK903. HER2 staining was also negative. Based on pathology review and radiographic findings, this patient was diagnosed with stage IV urachal mucinous adenocarcinoma metastatic to the bone marrow with possible metastases to the liver and lung as well.

\section{TREATMENT}

This patient was ultimately treated with a gastrointestinal chemotherapy regimen commonly known as FOLFOX-6 (Folinic acid, fluorouracil and oxaliplatin) every 14 days. Oxaliplatin was stopped after 12 cycles due to significant peripheral neuropathy. The patient was subsequently continued on maintenance therapy with 5 -fluorouracil with the plan to continue fluorouracil-based treatment until progression of disease.

\section{OUTCOME AND FOLLOW-UP}

Restaging CT scan of the chest, abdomen and pelvis around 6 months after starting the aforementioned treatment regimen revealed a stable urachal mass without significant change in size, stable pulmonary nodules and slightly increased size of the hypodensities throughout the liver. His blood counts also improved with haemoglobin around $100 \mathrm{~g} / \mathrm{L}$ and improved dyspnoea on exertion.

\section{DISCUSSION}

There is no validated staging system for urachal cancer; however, the two most commonly used are the Sheldon staging system proposed in 1984 and the Mayo staging system proposed by Ashley et al. (table 1). ${ }^{571315}$

Surgery is the mainstay of therapy if localised and surgically resectable, although one-third of patients are unresectable at the time of presentation. Urachal tumours are not very radiosensitive, therefore radiotherapy is infrequently used. ${ }^{7}$ If localised and surgically resectable, a partial cystectomy with en-bloc urachectomy and umbilectomy, involving resection of the medial umbilical ligament from the bladder dome up to, and including, the umbilicus, with negative surgical margins is widely considered to be the recommended surgical approach. ${ }^{8} 1617$ Margin-negative, en bloc resection is believed to have a significant impact on survival with several studies suggesting an increased risk of relapse when this procedure is not performed. ${ }^{11}$

Unfortunately, patients with urachal cancer often present with locally advanced or metastatic disease. However, there are limited reports of urachal cancer metastatic to the bone marrow. Bone marrow metastasis is rare, in and of itself, and patients often have a poor prognosis due to rapid disease progression and poor response to treatment. ${ }^{18}$ The most common origins of bone marrow metastasis include lung, breast, stomach and prostate. ${ }^{19}$ Chandra et al performed a retrospective study of 1419 cases that underwent bone marrow evaluation from 2006 to 2009 due to various diseases and found only 25 cases of bone marrow metastasis from solid tumours, constituting just $1.76 \%$ of all cases. ${ }^{20}$ Additionally, Anner et al evaluated 3620 bone marrow aspirates from 2877 patients with solid tumours and found 263 cases of bone marrow metastasis making up 9.1\% of all cases. ${ }^{21}$ Kucukzeybek et al also performed a retrospective evaluation of a total of 3345 bone marrow biopsies and found only 58 patients with bone marrow metastasis of solid tumours with a median overall survival of just 28 days after bone marrow metastasis was discovered. ${ }^{19}$ Similarly, Zhou et al reviewed 30 patients with bone marrow metastasis and found a median overall survival time of 3 months with a median overall survival time of 9 months in the systemic therapy group. ${ }^{18}$ Taylor et al described one of the few reported cases of urachal adenocarcinoma with evidence of isolated thoracic vertebral metastasis and bone marrow involvement on biopsy; however, this patient underwent vertebral corpectomy and received no systemic chemotherapy. ${ }^{22}$

Patients with urachal adenocarcinoma metastatic to the bone marrow are not surgical candidates and chemotherapy remains the primary treatment modality in these patients. However, the role of chemotherapy in urachal cancer is not well established and there are currently no evidence-based guidelines regarding neoadjuvant
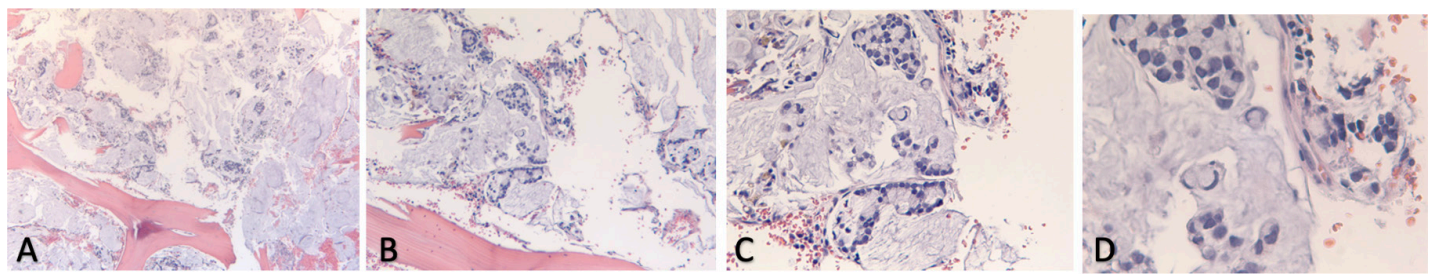

Figure 2 Bone marrow aspirate and biopsy revealed $90 \%-95 \%$ of the marrow space replaced by large lakes of mucin within which there were floating small round glandular structures composed of malignant cells with mucinous cytoplasmic vacuoles. The tumour cells included frequent signet ring forms. The little remaining bone marrow was hypercellular with maturing myeloid and erythroid precursors, likely representing erythroid hyperplasia. 


\begin{tabular}{|c|c|c|}
\hline Stage & Sheldon staging system & Mayo staging system \\
\hline I & Confined to urachal mucosa & Confined to urachus and/or bladder \\
\hline II & Invasion confined to urachus itself & $\begin{array}{l}\text { Extending beyond the muscular layer of } \\
\text { urachus and/or bladder }\end{array}$ \\
\hline III & - & Infiltrating regional lymph nodes \\
\hline IIIA & Local extension to bladder & - \\
\hline IIIB & Local extension to abdominal wall & - \\
\hline IIIC & Local extension to peritoneum & - \\
\hline IIID & $\begin{array}{l}\text { Local extension to viscera other than } \\
\text { the bladder }\end{array}$ & - \\
\hline IV & - & $\begin{array}{l}\text { Infiltrating non-regional lymph nodes or } \\
\text { other distant sites }\end{array}$ \\
\hline IVA & Metastatic to lymph nodes & - \\
\hline IVB & Metastatic to distant sites & - \\
\hline
\end{tabular}

or adjuvant chemotherapy for the treatment of urachal cancer. ${ }^{712}$ However, there is evidence to suggest that urachal cancer is less responsive to cisplatin-based chemotherapy when compared with urothelial cancer. ${ }^{6}$ Szarvas et al conducted a comprehensive metaanalysis of over 1000 cases of urachal cancer and found a higher radiographic response rate in the 5-fluorouracil-based chemotherapy regimens when compared with the cisplatin-based chemotherapy regimens $(44 \%$ vs $9 \%, \mathrm{p}=0.043)$ with the combination of both 5 -fluorouracil and cisplatin chemotherapy demonstrating the lowest progression rate $(14 \%)$ with a radiographic response rate of $43 \% .{ }^{13}{ }^{16}$ Histology, immunohistochemical staining and clinical presentation of urachal cancer classically resembles colorectal cancer and is often treated similarly. ${ }^{11}$ Given this resemblance, there have been several reports of metastatic urachal cancer responding to FOLFOX chemotherapy. ${ }^{712} 2324$

The patient described in this case report demonstrates a rare case of urachal adenocarcinoma with bone marrow metastasis. Given the generally poor prognosis of both urachal cancer and bone marrow metastasis, when evaluated separately, one would surmise that prognosis would be similarly poor for a patient with both. Additionally, this patient presented with presumed metastases to the lungs and liver. The patient in this case report was classified as stage IVB based on the Sheldon staging system and stage IV based on the Mayo staging system discussed previously. Given the diffuse metastases, this patient was not considered to be a surgical candidate. Therefore, he was treated with chemotherapy (FOLFOX-6). This case report demonstrates a patient with urachal adenocarcinoma with bone marrow metastasis treated with fluorouracil-based chemotherapy without significant progression of disease after 6 months of treatment.

\section{Learning points}

- Given the rarity of urachal cancer, one of the challenges is that medical case studies provide one of the few sources of literature through which clinicians have to guide medical management.

- This was a rare case demonstrating that urachal adenocarcinoma can metastasise to the bone marrow which may present as pancytopenia.

- This case demonstrates use of 5-fluorouracil based chemotherapy in a patient with urachal adenocarcinoma with bone marrow metastasis.
Contributors The author would like to thank Dr Brian Byrne, MD, for his contributions with analysis and interpretation of data and review of this case report.

Funding The authors have not declared a specific grant for this research from any funding agency in the public, commercial or not-for-profit sectors.

Competing interests None declared.

\section{Patient consent for publication Obtained.}

Provenance and peer review Not commissioned; externally peer reviewed.

Open access This is an open access article distributed in accordance with the Creative Commons Attribution Non Commercial (CC BY-NC 4.0) license, which permits others to distribute, remix, adapt, build upon this work non-commercially, and license their derivative works on different terms, provided the original work is properly cited and the use is non-commercial. See: http://creativecommons.org/ licenses/by-nc/4.0/

\section{REFERENCES}

1 Varma V, Myers DT. Urachal adenocarcinoma. Appl Radiol 2019:48:44-5.

2 Yu JS, Kim KW, Lee HJ, et al. Urachal remnant diseases: spectrum of CT and US findings. Radiographics 2001;21:451-61.

3 Rhudd A, Moghul M, Nair G, et al. Malignant transformation of a urachal cyst-a case report and literature review. J Surg Case Rep 2018;2018:rjy056.

4 Goljan EF. Chapter 21: Lower urinary tract and male reproductive disorders. In: Goljan EF, ed. Rapid review pathology. 528. 4 edn. Elsevier, 2014.

5 Palla Garcia J, Sampaio R, Peixoto C. Urachal tumor: a case report of an extremely rare carcinoma. Case Rep Pathol 2017;2017:1-5.

6 Siefker-Radkte AO, Czerniak BA, Dinney CP. Section 1: Genitourinary Cancer. Chapter 2: Uncommon Cancers of the Bladder. In: Raghavan D, Brecher ML, Johnson DH, eds. Textbook of uncommon cancer. 3 edn. John Wiley \& Sons Ltd, 2006: 24-5.

7 Hamilou Z, North S, Canil C, et al. Management of urachal cancer: a consensus statement by the Canadian urological association and genitourinary medical oncologists of Canada. Can Urol Assoc J 2020;14:E57-64.

8 Molina JR, Quevedo JF, Furth AF, et al. Predictors of survival from urachal cancer. Cancer 2007;110:2434-40.

9 Bruins HM, Visser 0, Ploeg M, et al. The clinical epidemiology of urachal carcinoma: results of a large, population based study. J Urol 2012;188:1102-7.

10 Reis H, Krafft U, Niedworok C, et al. Biomarkers in urachal cancer and adenocarcinomas in the bladder: a comprehensive review supplemented by own data. Dis Markers 2018;2018:1-21.

11 Siefker-Radtke AO, Czerniak BA, Dinney CP. Chapter 36: Bladder cancer. In: Kantarjian $\mathrm{H}$, Wolff RA, eds. The MD anderson manual of medical oncology. 3 edn. McGraw-Hill Education, 2016.

12 Paner GP, Lopez-Beltran A, Sirohi D, et al. Updates in the pathologic diagnosis and classification of epithelial neoplasms of urachal origin. Adv Anat Pathol 2016;23:71-83.

13 Szarvas T, Módos 0, Niedworok C, et al. Clinical, prognostic, and therapeutic aspects of urachal carcinoma-a comprehensive review with meta-analysis of 1,010 cases. Urol Oncol 2016;34:388-98.

14 Ashley RA, Inman BA, Sebo TJ, et al. Urachal carcinoma: clinicopathologic features and long-term outcomes of an aggressive malignancy. Cancer 2006;107:712-20.

15 Elser C, Sweet J, Cheran SK, et al. A case of metastatic urachal adenocarcinoma treated with several different chemotherapeutic regimens. Can Urol Assoc $J$ 2012;6:E27-31.

16 Siefker-Radtke A. Urachal adenocarcinoma: a clinician's guide for treatment. Semin Oncol 2012:39:619-24

17 Kumar N, Khosla D, Kumar R, et al. Urachal carcinoma: clinicopathological features, treatment and outcome. J Cancer Res Ther 2014;10:571-4.

18 Zhou MH, Wang ZH, Zhou HW, et al. Clinical outcome of 30 patients with bone marrow metastases. J Cancer Res Ther 2018;14:512-5.

19 Kucukzeybek BB, Calli AO, Kucukzeybek Y, et al. The prognostic significance of bone marrow metastases: evaluation of 58 cases. Indian J Pathol Microbiol 2014:57:396-9.

20 Chandra S, Chandra H, Saini S. Bone marrow metastasis by solid tumors--probable hematological indicators and comparison of bone marrow aspirate, touch imprint and trephine biopsy. Hematology 2010;15:368-72.

21 Anner RM, Drewinko B. Frequency and significance of bone marrow involvement by metastatic solid tumors. Cancer 1977;39:1337-44.

22 Taylor S, Bacchini P, Bertoni F. An isolated vertebral metastasis of urachal adenocarcinoma. Arch Pathol Lab Med 2004;128:1043-5.

23 Yanagihara Y, Tanji N, Miura N, et al. Modified FOLFOX6 chemotherapy in patients with metastatic urachal cancer. Chemotherapy 2013;59:402-6.

24 Tran B, McKendrick J. Metastatic urachal cancer responding to FOLFOX chemotherapy. Can J Urol 2010;17:5120-3. 
Copyright 2021 BMJ Publishing Group. All rights reserved. For permission to reuse any of this content visit https://www.bmj.com/company/products-services/rights-and-licensing/permissions/

BMJ Case Report Fellows may re-use this article for personal use and teaching without any further permission.

Become a Fellow of BMJ Case Reports today and you can:

- Submit as many cases as you like

- Enjoy fast sympathetic peer review and rapid publication of accepted articles

Access all the published articles

- Re-use any of the published material for personal use and teaching without further permission

Customer Service

If you have any further queries about your subscription, please contact our customer services team on +44 (0) 2071111105 or via email at support@bmj.com.

Visit casereports.bmj.com for more articles like this and to become a Fellow 